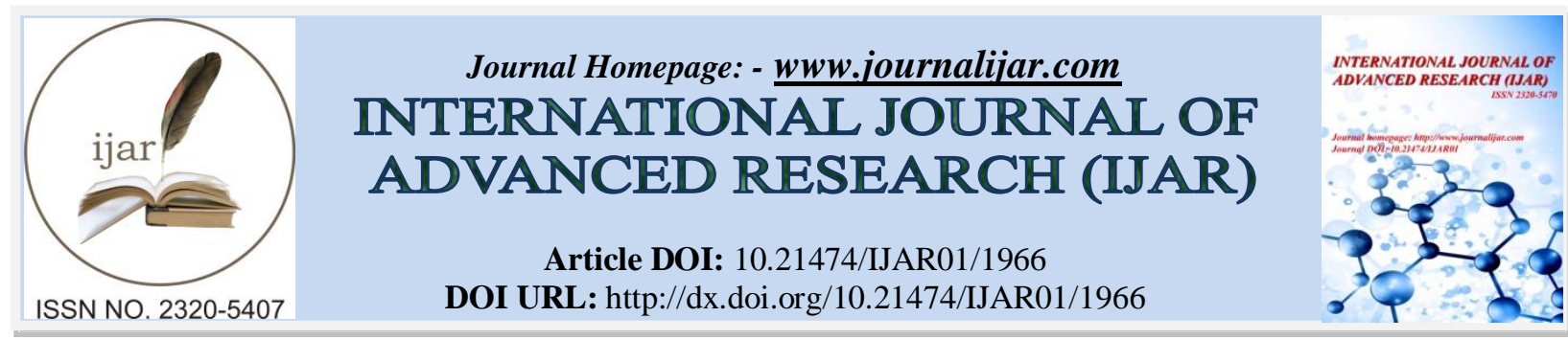

RESEARCH ARTICLE

\title{
EXPERIMENTAL AND COMPUTATIONAL STUDIES ON THE CORROSION INHIBITON OF MILD STEEL BY HYDRAZONES IN $2 \mathrm{M}$ HCl.
}

\section{K. Raja ${ }^{1}$, A. N. Senthil kumar ${ }^{2}$, S. Umamatheswari ${ }^{1}$ and ${ }^{*}$ K. Tharini ${ }^{1}$.}

1. PG and Research Department of Chemistry, Government Arts College, Trichy-620022, India.

2. PG \& Research Department of Chemistry, Alagappa Govt. Arts College, Karaikudi- 630 003, India.

\section{Manuscript Info}

Manuscript History

Received: 11 August 2016

Final Accepted: 22 September 2016

Published: October 2016

Key words:-

$\mathrm{BPPH}, \mathrm{BPH}$, Weight loss, polarization, Ionization potential, SEM ,quantum chemical studies.

\begin{abstract}
The title compounds N-benzyl piperidine -4- one phenyl hydrazone $(\mathrm{BPPH})$ and N-benzyl piperidine -4-one hydrazone (BPH) were used to control mild steel corrosion in $2 \mathrm{M} \mathrm{HCl}$ solutions at different temperatures $(303 \mathrm{~K}-333 \mathrm{~K})$. The corrosion inhibitory effect of the compounds has been investigated by weight loss study, electrochemical methods, SEM and quantum chemical studies. The weight loss studies were conducted at four different temperatures such as $303 \mathrm{~K}, 313 \mathrm{~K}$, $323 \mathrm{~K}$ and $333 \mathrm{~K}$ for various concentrations of $(0,25,50,100,200$ and $300 \mathrm{ppm}$ ) for $1 \mathrm{~h}$ and $2 \mathrm{~h}$ duration. The study showed that inhibition efficiency increases with increase of BPPH and BPH concentration and decreases with increase of temperature. It was found that inhibition was due to adsorption of BPPH and BPH on the MS surface obeying Temkin's adsorption isotherm. Electrochemical data for corrosion processes such as corrosion potential( $\left.\mathrm{E}_{\text {corr }}\right)$, corrosion current $\left(\mathrm{i}_{\text {corr }}\right)$ and Tafel slopes $\left(b_{a}\right.$ and $\left.b_{c}\right)$ were determined using Tafel plot, which showed that increase in concentration of BPPH and BPH decreases corrosion current and behaves as mixed mode inhibitor. AC impedance measurement as determined by Nyquist plot revealed that charge transfer resistance increases with increase of concentration, whereas double layer capacitance decreases with increase of concentration complimenting each other. SEM studies revealed the surface protecting ability of BPPH and BPH in acid medium. Quantum chemical studies illustrated that the corrosion inhibition efficiency of BPPH and BPH is due to lone pair of electrons of two nitrogen in the hydrazone moiety $\Pi$ electron of phenyl ring and ring nitrogen
\end{abstract}

Copy Right, IJAR, 2016,. All rights reserved.

\section{Introduction:-}

Mild steel is one of the most widely used metals in most of the industries, are often exposed to the action of acids during industrial process such as acid cleaning, descaling and acid pickling. This has led to corrosion of mild steel proving the necessity for an inhibitor ${ }^{1-5}$. Corrosion inhibitors are widely used in acid solutions for protection of metal surfaces from corrosion. Several organic compounds with hetero atoms like O, N, S, P and having multiple bonds are useful and are widely used as effective corrosion inhibitors ${ }^{6}$. In different acid solutions the corrosion inhibition of metals generally depends on how the metals are interacting with the concerned organic molecule ${ }^{7}$ The 
organic molecules should have centres which are capable of forming coordination bonds with metal surfaces . Stronger is the coordination bond, better is the inhibition efficiency. Their effectiveness as promising inhibitors is related to spatial molecular structural distribution, molecular electronic structure, chemical composition, surface charge density and of course to their affinity to the individual metal surface ${ }^{8}$. Quantum chemical studies were also carried out to ascertain whether the experimental results are fully supported by theoretical predictions by finding a clear relationship between calculated quantum chemical parameters and experimentally determined inhibition efficiency of inhibitors. This is achieved by calculating relevant molecular properties of inhibitors and there by explaining the mechanism of inhibition of the inhibitors with the steel surface. The objective here is to control the corrosion of a mild steel in $2 \mathrm{M} \mathrm{HCl}$ solution using a novel synthesized $\mathrm{N}$-benzyl piperidne-4- one hydrazones.

\section{Experimental}

Procedure for preparation of N-benzyl piperidine -4-one hydrazone (BPH)

To the boiling solution of N-benzyl piperidine -4 -one $(0.01 \mathrm{~mol})$ in methanol $(45 \mathrm{ml})$ and few drops of concentrated hyrocholoric acid the methanolic solution of hydrazine di hydrocholoride $(0.01 \mathrm{~mol})$ was added drop wise by stirring .The reaction was refluxed for $4 \mathrm{hrs}$ on a water bath. After cooling the solid product was filtered and recrystallized from methanol to get the corresponding hydrazone.

\section{Procedure for preparation of Phenyl hydrazone}

To the boiling solution of N-benzyl piperidine -4-one $(0.01 \mathrm{~mol})$ in methanol $(45 \mathrm{ml})$ and few drops of concentrated hydrochloric acid, the methanolic solution of phenyl hydrazine hydrochloride $(0.01 \mathrm{~mol})$ was added drop wise by stirring . The reaction was refluxed for $4 \mathrm{hrs}$ on a water bath. After cooling the solid product was filtered and recrystallized from methanol to get the corresponding phenyl hydrazone.

Table-1:- Characterisation of N-benzyl piperidin-4-one derivatives

\begin{tabular}{|l|l|l|l|}
\hline Compound Name & Yield(\%) & $\begin{array}{l}\text { Melting } \\
\left.\text { point }{ }^{\mathbf{0}} \mathbf{C}\right)\end{array}$ & Elemental analysis \\
\hline $\begin{array}{l}\text { N-benzyl piperidin-4-one } \\
\text { hydrazone }\end{array}$ & 96 & $196-198$ & $\mathrm{C}(\%) \mathbf{7 0 . 8 3} \mathrm{H}(\%) \mathbf{8 . 4 0} \mathrm{N}(\%) \mathbf{2 0 . 7 9}$ \\
\hline $\begin{array}{l}\text { N-benzyl piperidin-4-one } \\
\text { phenylhydrazone }\end{array}$ & 86 & $163-165$ & $\mathrm{C}(\%) \mathbf{7 7 . 5 3} \mathrm{H}(\%) 7.10 \mathrm{~N}(\%) \mathbf{1 5 . 1 9}$ \\
\hline
\end{tabular}

\section{Spectral analysis:-}

N-benzyl piperidin-4-one hydrazone:-

Yield: 96\% ; IR $\left(\mathbf{c m}^{-\mathbf{1}}\right)$ : $3259\left(\mathrm{NH}_{2}\right.$ stretching); $1622\left(\mathrm{C}=\mathrm{N}\right.$ stretching); ${ }^{\mathbf{1}} \mathbf{H}$ NMR $(\boldsymbol{\delta} \mathbf{~ p p m}):$ yield :96\% $3.68(\mathrm{~d}$, 2H, H-2, J = 6.0 Hz); 3.49 (t, 2H, H-6); 3.11 (m, 2H, H-3); 2.76 (t, 2H, H-5); 4.67 (s, 2H, -N-CH $-\mathrm{Ph}$ ); 7.48-7.43 (m, 5H, aryl protons). ${ }^{13} \mathbf{C}$ NMR $(\mathbf{\delta} \mathbf{~ p p m}): 49.10(\mathrm{C}-2) ; 48.29(\mathrm{C}-6) ; 32.97(\mathrm{C}-3) ; 27.43(\mathrm{C}-5) ; 155.31(\mathrm{C}=\mathrm{N}) ; 60.81(-$ $\mathrm{N}-\mathrm{CH}_{2}-\mathrm{Ph}$ ); $131.38-128.24$ (aromatic carbons).

\section{N-benzyl piperidin-4-one phenyl hydrazone:-}

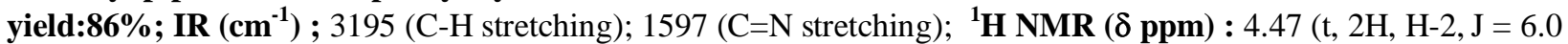
$\mathrm{Hz}$ ); 3.17 (t, 2H, H-6); 2.72 (t, 2H, H-3); 2.00 (t, 2H, H-5); 4.36 (s, 2H, -N-CH $-\mathrm{Ph}$ ); 4.29 (s, 1H, OH proton)7.48$7.43\left(\mathrm{~m}, 10 \mathrm{H}\right.$, aryl protons). ${ }^{13} \mathbf{C}$ NMR $(\boldsymbol{\delta} \mathbf{~ p p m}): 51.82(\mathrm{C}-2) ; 49.81(\mathrm{C}-6) ; 30.08(\mathrm{C}-3) ; 23.19(\mathrm{C}-5) ; 145.57(\mathrm{C}=\mathrm{N})$; $60.26\left(-\mathrm{N}-\mathrm{CH}_{2}-\mathrm{Ph}\right) ; 131.18-115.59$ (aromatic carbons).

\section{Electro chemical studies:-}

Weight loss method:-

Weight loss experiments were conducted on test MS coupons of dimension $4 \times 1 \times 0.2 \mathrm{~cm}$. The precleaned and weighed coupons were suspended in beakers containing the test solutions using glass hooks and rods. Tests were conducted under total immersion conditions in $100 \mathrm{~mL}$ of the aerated and unstirred test solutions. To determine weight loss with respect to time, the coupons were retrieved from test solutions at $1 \mathrm{hrs}$ and $2 \mathrm{hrs}$ intervals, appropriately cleaned, dried, and reweighed. The weight loss was taken to be the difference between the weight of the coupons at a given time and its initial weight. All tests were run in duplicates and the data showed good reproducibility. Average values for each experiment were obtained and used in subsequent calculations. 


\section{Polarisation and impedance studies:-}

Potentiodynamically, the polarization curves were recorded using computerized CHi $604 \mathrm{c}$ model. In this set up Pt electrode, calomel electrode and MS specimens were used as auxiliary, reference and working electrodes respectively which were immersed in the presence and absence of BPPH and BPH. Impedance studies were carried out in the frequency range of $10 \mathrm{KHz}$ to $10 \mathrm{mHz}$ for $\mathrm{MS}$ in $2 \mathrm{M} \mathrm{HCl}$ with and without different concentrations of $\mathrm{BPPH}$ and $\mathrm{BPH}$. IE was calculated using $\mathrm{R}_{\mathrm{ct}}$ as follows

$$
\mathrm{IE}=1-\frac{\mathrm{R}_{\text {cto }}}{\mathrm{R}_{\mathrm{cti}}} \mathrm{X} 100
$$

where $\mathrm{R}_{\text {cto }}$ - charge transfer resistance in absence of BPPH and BPH.

$\mathrm{R}_{\mathrm{cti}}-$ charge transfer resistance in presence of various concentration of $\mathrm{BPPH}$ and $\mathrm{BPH}$.

\section{Scanning Electron Microscopy (SEM)}

SEM micrographs were taken using computerized electron microscope of make Philips XL series.

\section{Quantum chemical studies:-}

The quantum chemical study was done using B3LYP/6-31g(d) at DFT method, commercially available computer package program in an Intel Pentium duo core processor computer.

\section{Results And Discussion:-}

The calculated values of IE and CR for BPPH and BPH inhibition for MS dissolution in $\mathrm{HCl}$ medium is depicted in Table 2. From the table it is clear that IE increases with increase of BPPH and BPH concentration. ${ }^{10}$ Increase of IE with increase of BPPH and BPH concentration showed that the corrosion is controlled by adsorption process. (Fig 18) Several adsorption isotherms were tested with the experimental results and the Temkin's isotherm was found to be the best (fig 12 and 13). Decrease of IE with increase of temperature supports physisorption process. ${ }^{11}$ Tafel polarization curves of $\mathrm{MS}$ in $2 \mathrm{M} \mathrm{HCl}$ solution with different concentrations of $\mathrm{BPPH}$ and $\mathrm{BPH}$ are shown in Figure 10 and 12. Increase in concentration of BPPH and BPH causes shifting of corrosion potential on both the directions indicating mixed mode inhibiting action of BPPH and BPH. No particular trend was observed from Tafel constants, which is suggestive of mixed mode inhibition. $i_{\text {corr }}$ values decreased with increase of BPPH and BPH concentration which indicates the corrosion controlling property of BPPH and BPH ( Table 3). Nyquist plots in the presence and absence of various concentrations of BPPH and BPH in $2 \mathrm{M} \mathrm{HCl}$ is depicted in fig 9 and11. The dispersion obtained in Nyquist plot was due to the dispersive capacitive loop and the homogeneities on the electrode surface ${ }^{12-15} R_{c t}$ increases with increase of BPPH and BPH concentration whereas $\mathrm{C}_{\mathrm{dl}}$ decreases with increase of BPPH and BPH concentration indicating the protection efficiency of BPPH and BPH .

SEM micrographs are shown in Figures 15-17 for MS specimen exposed to 2M HCl and MS exposed to $300 \mathrm{ppm}$ of $\mathrm{BPPH}$ and $\mathrm{BPH}$ in $2 \mathrm{M} \mathrm{HCl}$.

All the calculations were done by means of B3LYP/6-31g(d) at DFT method program. These methods can reach exactitude similar to other methods in less time and with a smaller investment from the computational point of view . This approach is shown to yield favourable geometries for a wide variety of systems. This basis set gives good geometry optimizations. The geometry structure was optimized under no constraint. The following quantum chemical parameters were calculated from the obtained optimized structure: The highest occupied molecular orbital $\left(\mathrm{E}_{\mathrm{HOMO}}\right)$ and the lowest unoccupied molecular orbital $\left(\mathrm{E}_{\mathrm{LUMO}}\right)$, the energy difference $(\Delta \mathrm{E})$ between $\mathrm{E}_{\mathrm{HOMO}}$ and $\mathrm{E}_{\text {LUMO }}$, dipole moment $(\mu)$, electro negativity $(\chi)$, electron affinity $(A)$, global hardness $(\eta)$, global softness $(\sigma)$, ionization potential $(\mathrm{I})$, the fraction of electrons transferred $(\Delta \mathrm{N})$, global electrophilicity index $(\omega)$ and the total energy (TE). From the investigation it was observed that BPPH (I) exhibited more inhibition efficiency compare to $\mathrm{BPH}$ (II) .The efficiency implying that the ability of BPPH to offer lone pair of electrons of two nitrogen in the hydrazone moiety $\Pi$ electron of phenyl ring and ring nitrogen 
Table 2:- Calculated values of corrosion rate and inhibition efficiency for mild steel in $2 \mathrm{M} \mathrm{HCl}$ in the absence and presence of $B P P H$ and $B P H$ at $303 K-333 K$

\begin{tabular}{|c|c|c|c|c|c|c|c|c|}
\hline \multicolumn{9}{|l|}{ BPPH $\quad(1 \mathrm{hr})$} \\
\hline \multirow[t]{2}{*}{ Concentration } & \multicolumn{2}{|c|}{$303 \mathrm{~K}$} & \multicolumn{2}{|l|}{$313 \mathrm{~K}$} & \multicolumn{2}{|c|}{$323 \mathrm{~K}$} & \multicolumn{2}{|l|}{$333 \mathrm{~K}$} \\
\hline & IE & $\begin{array}{l}\mathrm{CR} \\
\end{array}$ & IE & \begin{tabular}{|l|}
$\mathrm{CR}$ \\
\end{tabular} & IE & CR & IE & CR \\
\hline 25 & 60.1 & 0.18 & 52.68 & \begin{tabular}{|l|}
0.23 \\
\end{tabular} & 49.56 & 0.28 & 48.51 & 0.33 \\
\hline 50 & 65.1 & 0.16 & 54.75 & 0.22 & 53.55 & 0.25 & 50.84 & 0.32 \\
\hline 100 & 70.63 & 0.13 & 59.44 & \begin{tabular}{|l|}
0.2 \\
\end{tabular} & 56.67 & 0.24 & 52.41 & 0.31 \\
\hline 200 & 73.8 & 0.12 & 61.93 & \begin{tabular}{|l|}
0.19 \\
\end{tabular} & 58.55 & 0.23 & 54.88 & $\begin{array}{ll}0.29 \\
\end{array}$ \\
\hline 300 & 81.18 & 0.08 & 64.82 & 0.17 & 59.92 & 0.22 & 57.43 & 0.27 \\
\hline \multicolumn{9}{|l|}{ BPPH (2 hrs) } \\
\hline 25 & 64.36 & 0.21 & 54.30 & \begin{tabular}{|l|l}
0.24 \\
\end{tabular} & 50.11 & 0.31 & 48.97 & 0.33 \\
\hline 50 & 65.50 & 0.21 & 55.93 & 0.23 & 53.05 & 0.30 & 50.13 & 0.32 \\
\hline 100 & 72.48 & 0.20 & 58.84 & 0.22 & 54.35 & 0.30 & 52.18 & 0.31 \\
\hline 200 & 74.80 & 0.20 & 59.81 & \begin{tabular}{|l|}
0.21 \\
\end{tabular} & 55.44 & 0.28 & 55.14 & 0.29 \\
\hline 300 & 77.08 & 0.17 & 60.79 & 0.21 & 55.87 & 0.28 & 58.04 & 0.27 \\
\hline \multicolumn{9}{|l|}{ BPH (1 hr) } \\
\hline 25 & 61.43 & 0.2 & 56.23 & 0.25 & 52.21 & 0.31 & 36.34 & 0.36 \\
\hline 50 & 76.07 & 0.12 & 58.35 & 0.24 & 54.53 & 0.3 & 37.31 & 0.35 \\
\hline 100 & 77.12 & 0.12 & 61.52 & 0.22 & 55.16 & 0.29 & 38.78 & 0.34 \\
\hline 200 & 78.43 & 0.11 & 62.82 & \begin{tabular}{|l|}
0.21 \\
\end{tabular} & 56.75 & 0.28 & 42.31 & 0.32 \\
\hline 300 & 83.79 & 0.08 & 64.23 & 0.21 & 57.7 & 0.27 & 44.14 & 0.31 \\
\hline \multicolumn{9}{|l|}{$\mathrm{BPH}$ (2 hrs) } \\
\hline 25 & 71.06 & 0.19 & 67.76 & \begin{tabular}{|l|l|}
0.28 \\
\end{tabular} & 65.09 & 0.33 & 60.07 & 0.38 \\
\hline 50 & 76.17 & 0.15 & 69.37 & 0.27 & 66.19 & 0.32 & 62.36 & 0.36 \\
\hline 100 & 77.7 & 0.14 & 69.96 & 0.26 & 66.98 & 0.31 & 63.45 & 0.34 \\
\hline 200 & 78.59 & 0.14 & 70.86 & 0.25 & 68.29 & 0.3 & 63.56 & 0.34 \\
\hline 300 & 83.97 & 0.1 & 71.56 & 0.25 & 68.76 & 0.29 & 64.54 & 0.36 \\
\hline
\end{tabular}

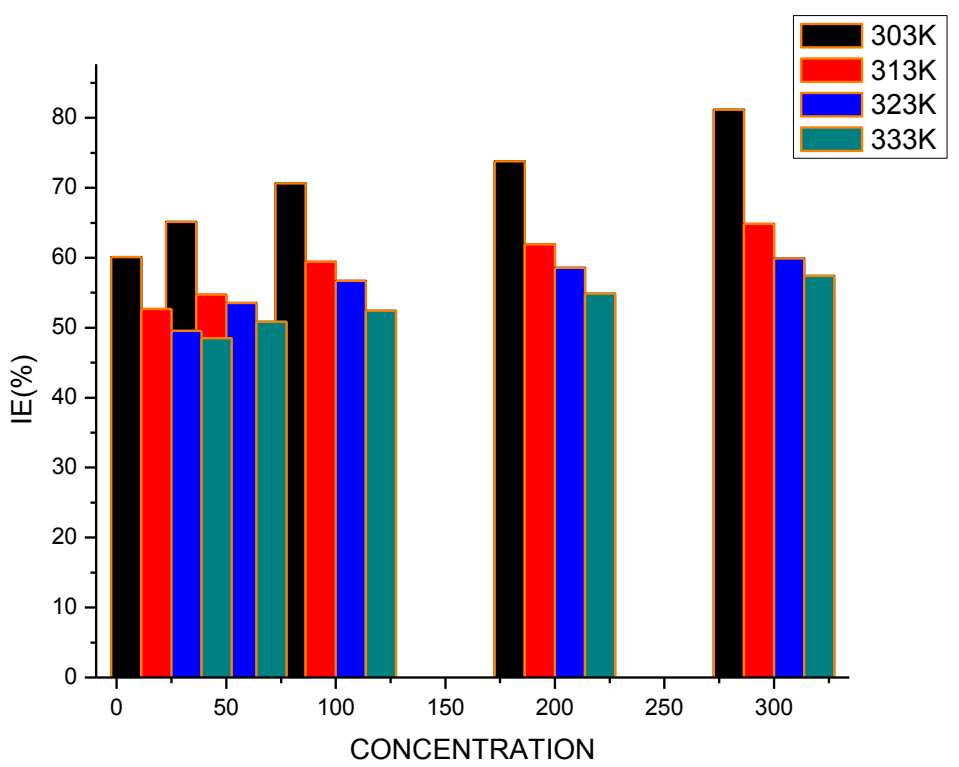

Fig: 1 Plot of \%Inhibition efficiency Vs concentration of (BPPH) at 1 hour duration 


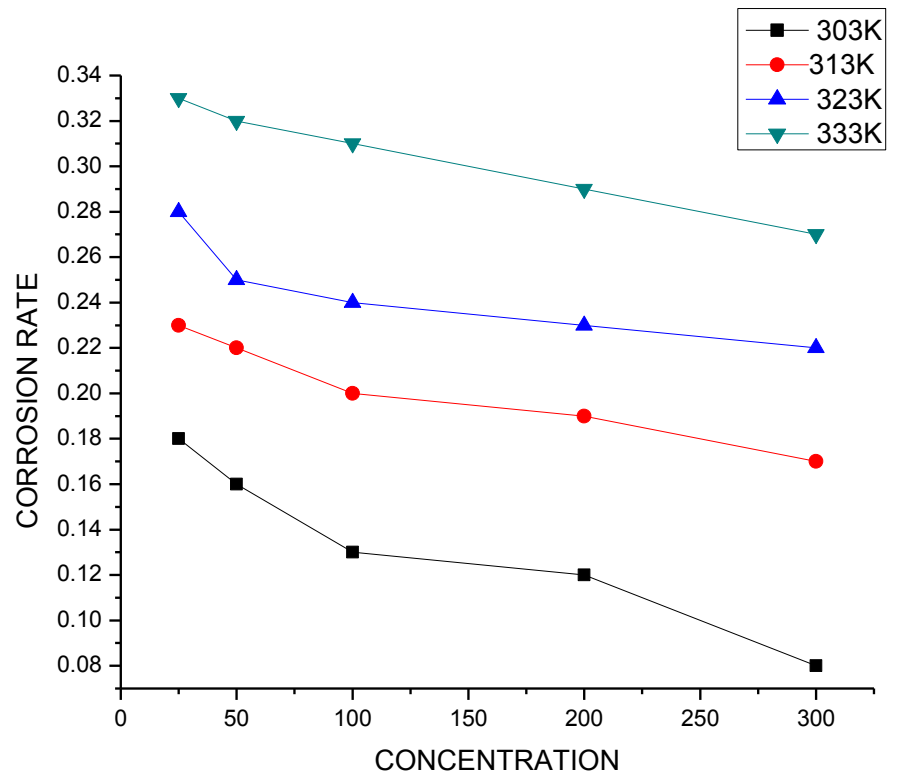

Fig: 2:- Plot of corrosion rate Vs concentration of $(\mathrm{BPPH})$ at 1 hour duration

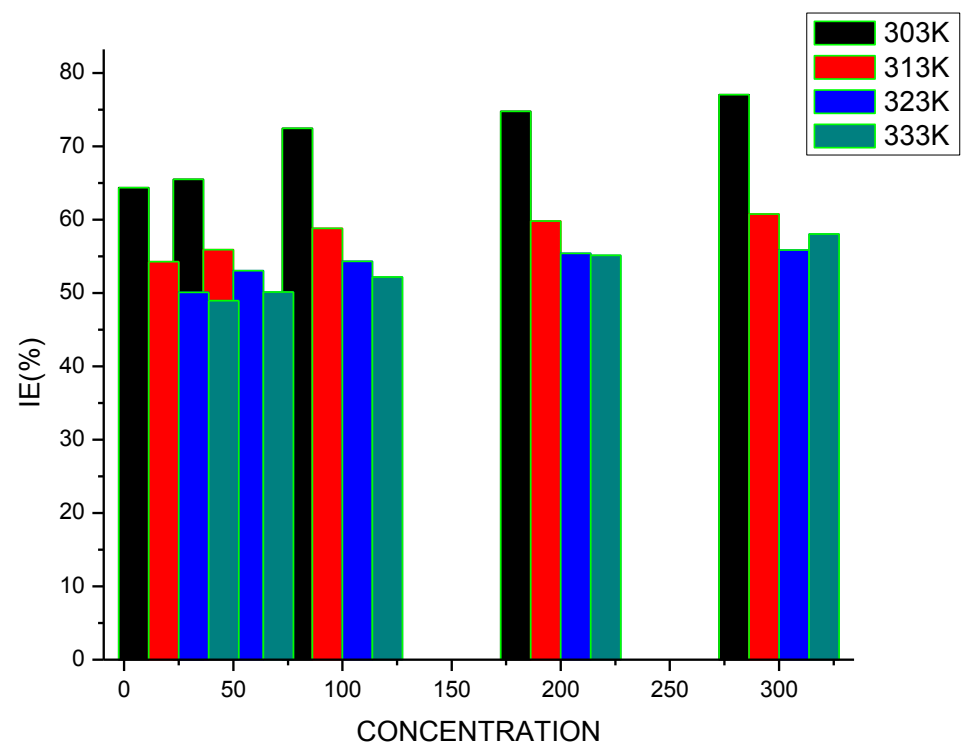

Fig: 3:- Plot of \%Inhibition efficiency Vs concentration of (BPPH) at 2 hour duration 


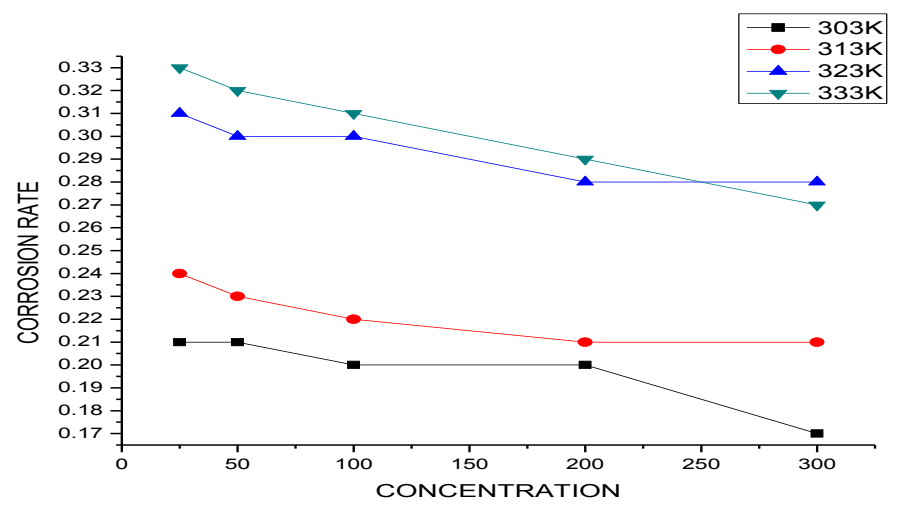

Fig: 4:- Plot of corrosion rate Vs concentration of (BPPH) at 2 hour duration

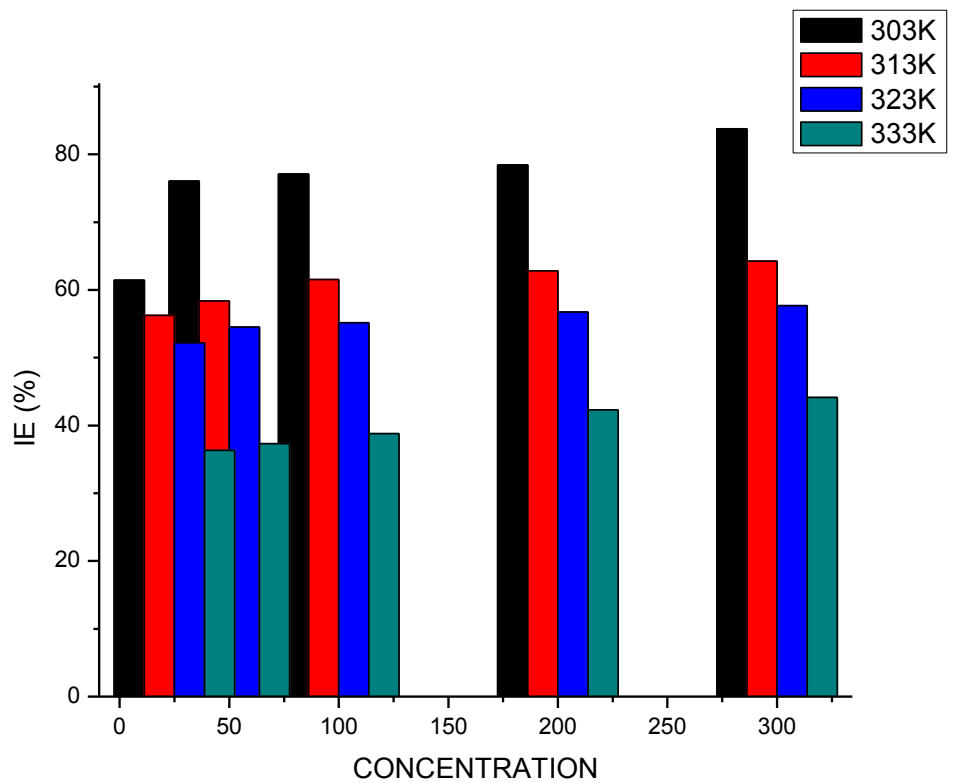

Fig: 5:- Plot of \%Inhibition efficiency Vs concentration of (BPH) at 1 hour duration 


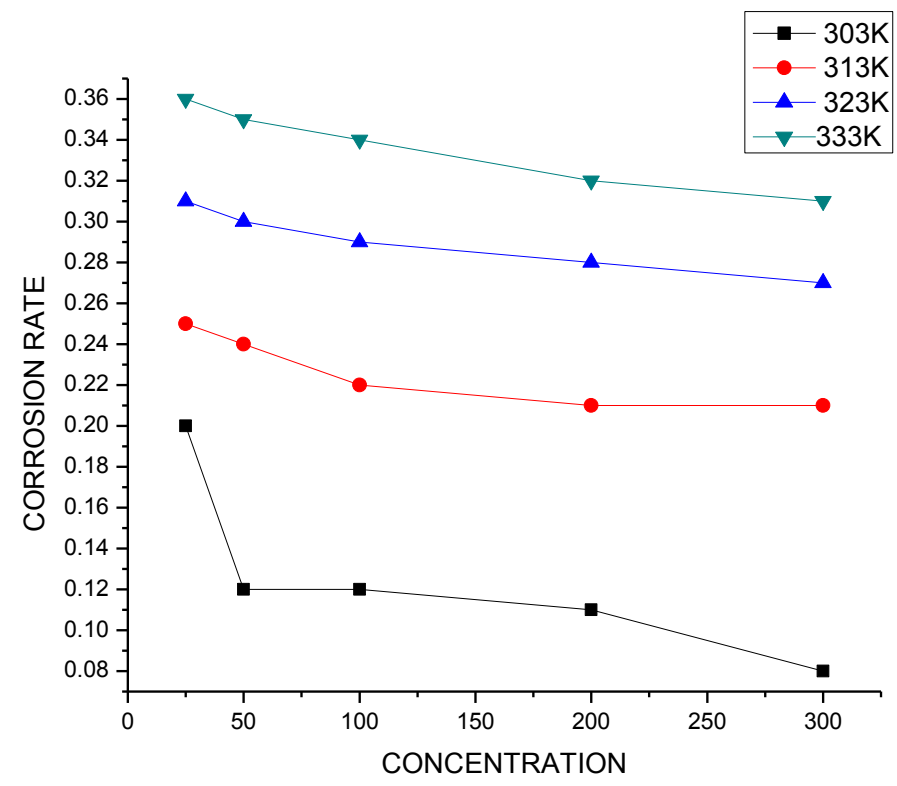

Fig: 6:- Plot of corrosion rate Vs concentration of (BPH) at 1 hour duration

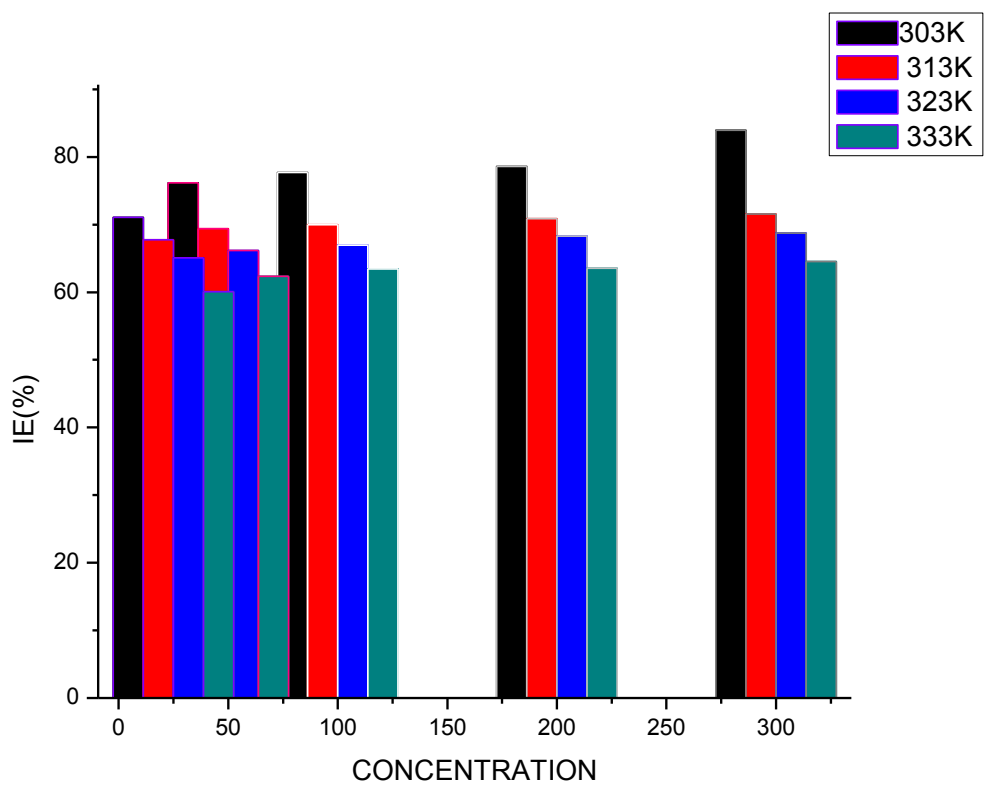

Fig: 7:- Plot of \%Inhibition efficiency Vs concentration of (BPH) at 2 hour duration 


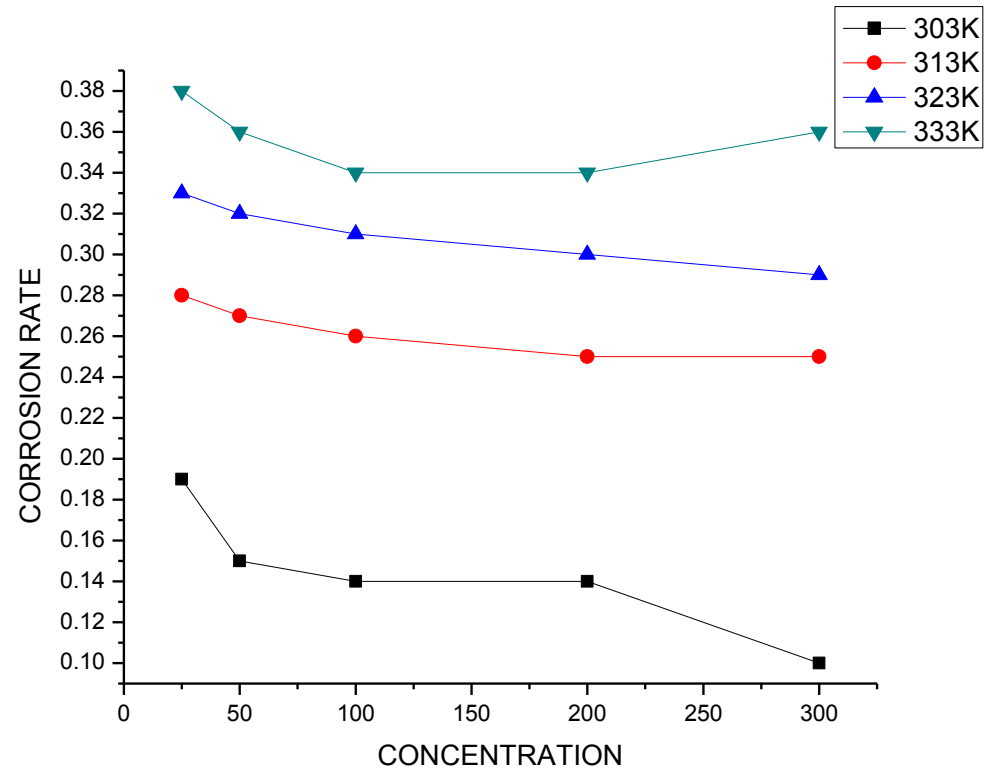

Fig: 8:- Plot of corrosion rate Vs concentration of (BPH) at 2 hour duration

Table 3:- Tafel plot of Electrochemical parameters of BPPH in $2 \mathrm{M} \mathrm{HCl}$ medium

\begin{tabular}{|c|c|c|c|c|c|c|c|c|}
\hline compound & $\begin{array}{l}\text { Concentration } \\
\text { of inhibitor (ppm) }\end{array}$ & $\begin{array}{l}-\mathbf{E}_{\text {corr }} \\
\mathrm{mV}\end{array}$ & $\begin{array}{l}I_{\text {corr }} \\
\mu \mathrm{Acm}^{-2}\end{array}$ & $\begin{array}{l}-b_{\mathrm{a}} \\
\mathbf{m V} \\
\text { dec }^{-1}\end{array}$ & $\begin{array}{l}-b_{c} \\
m V \\
\text { dec }^{-1}\end{array}$ & 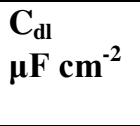 & $\begin{array}{l}\mathbf{R}_{\mathrm{ct}} \\
\mathbf{\Omega} \mathrm{cm}^{2}\end{array}$ & $\begin{array}{ll}\% & \text { of } \\
\text { IE }\end{array}$ \\
\hline \multirow{6}{*}{ ВРPH } & Blank & 443 & 255 & 53 & 29 & 124 & 60 & --- \\
\hline & 25 & 455 & 127 & 34 & 65 & 88 & 108 & 44.4 \\
\hline & 50 & 453 & 121 & 78 & 26 & 74 & 138 & 56.5 \\
\hline & 100 & 462 & 99 & 56 & 53 & 66 & 174 & 65.5 \\
\hline & 200 & 469 & 72 & 48 & 44 & 53 & 203 & 70.4 \\
\hline & 300 & 467 & 54 & 67 & 28 & 35 & 288 & 79.2 \\
\hline \multirow{6}{*}{ BPH } & Blank & 0.4971 & 1232 & 62 & 90 & 1805.22 & 9.23 & - \\
\hline & 25 & 0.4603 & 718.22 & 78 & 68 & 476.58 & 17.24 & 46.91 \\
\hline & 50 & 0.4582 & 355.24 & 45 & 52 & 292.99 & 36.15 & 74.72 \\
\hline & 100 & 0.4571 & 296.57 & 34 & 74 & 286.17 & 37.28 & 75.41 \\
\hline & 200 & 0.4546 & 258.96 & 92 & 83 & 285.93 & 45.23 & 79.77 \\
\hline & 300 & 0.4512 & 254.61 & 53 & 67 & 280.53 & 46.99 & 80.21 \\
\hline
\end{tabular}

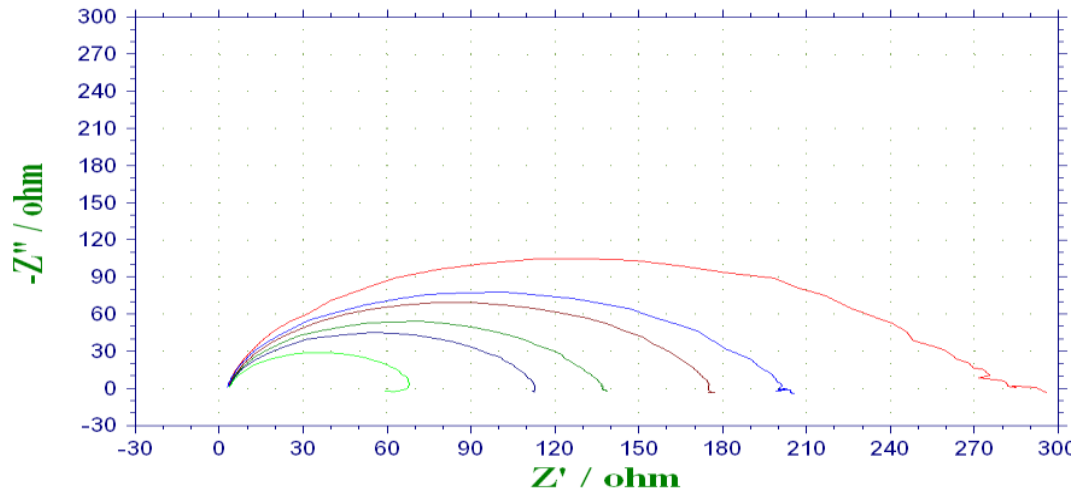

Fig. 9:- Nyquist plots for mild steel corrosion in $2 \mathrm{M}$ hydrochloric acid in the absence and the presence of various concentration of BPPH inhibitor 


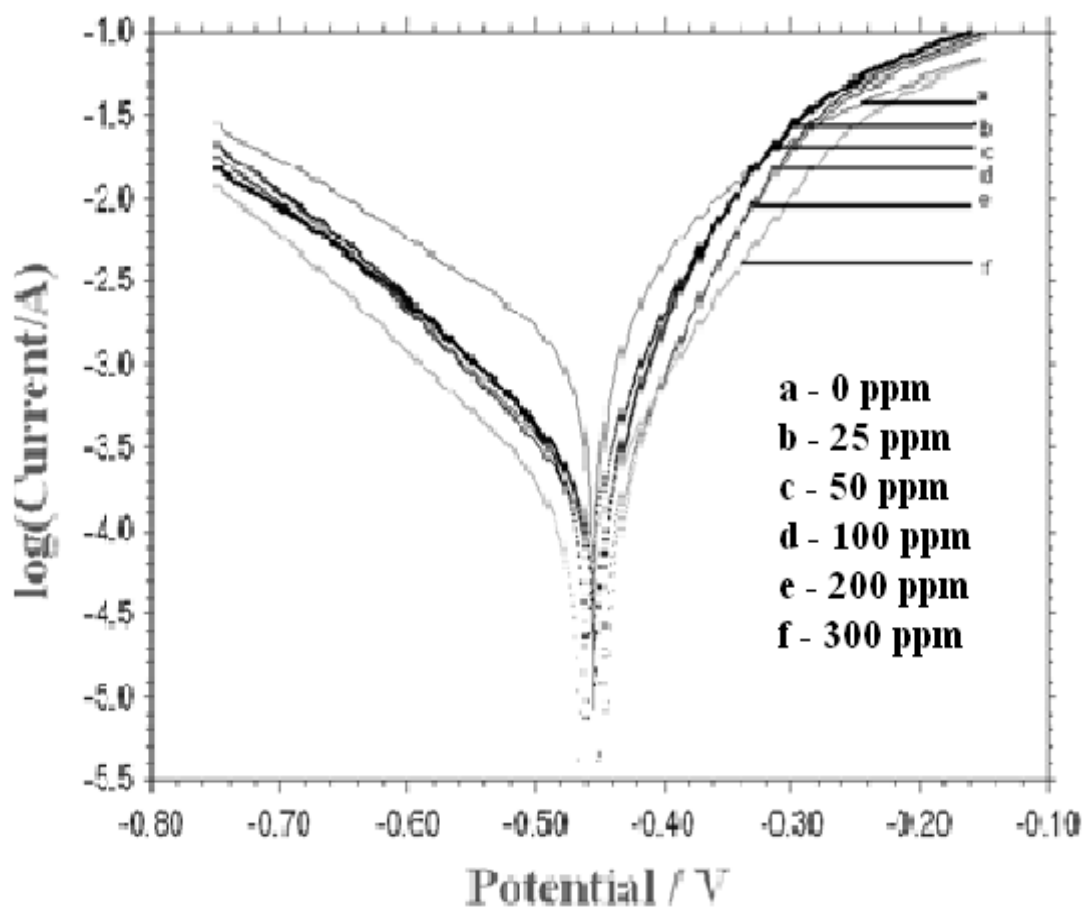

Fig. 10:- Tafel lines for mild steel corrosion in $2 \mathrm{M}$ hydrochloric acid in the absence and the presence of various concentration of BPPH inhibitor

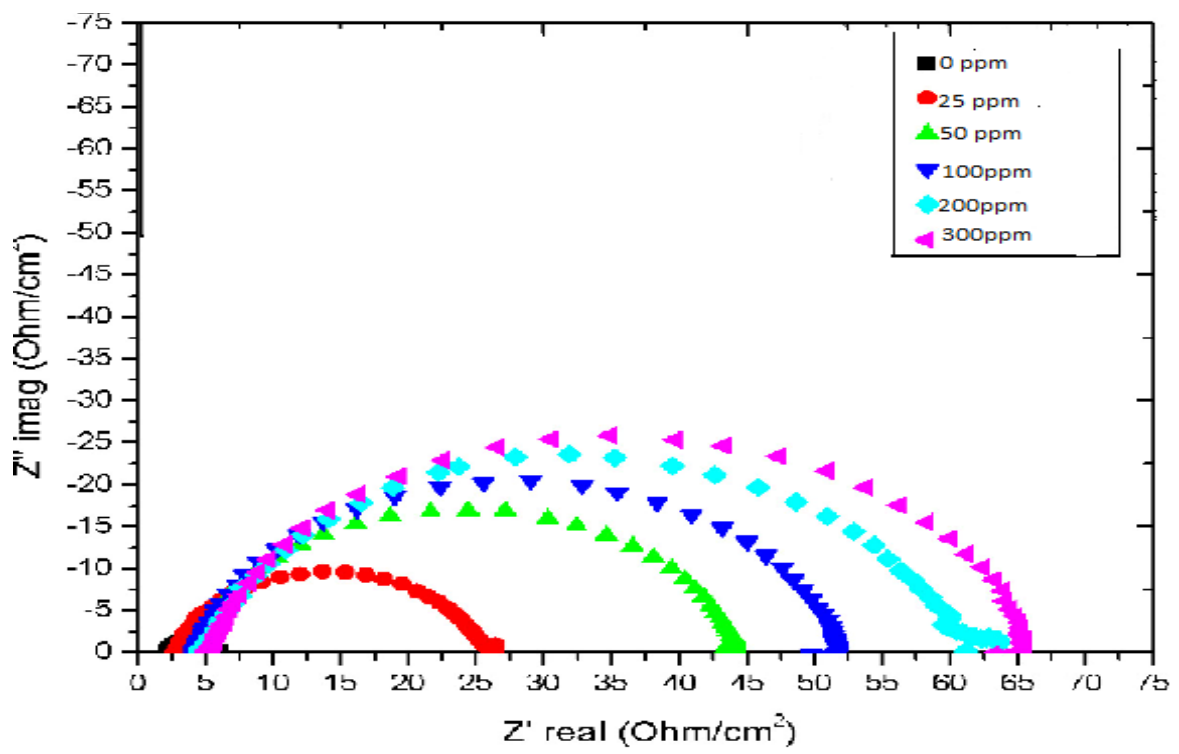

Fig. 11:- Nyquist plots for mild steel corrosion in $2 \mathrm{M}$ hydrochloric acid in the absence of the presence of various concentration of $\mathrm{BPH}$ inhibitor+ 


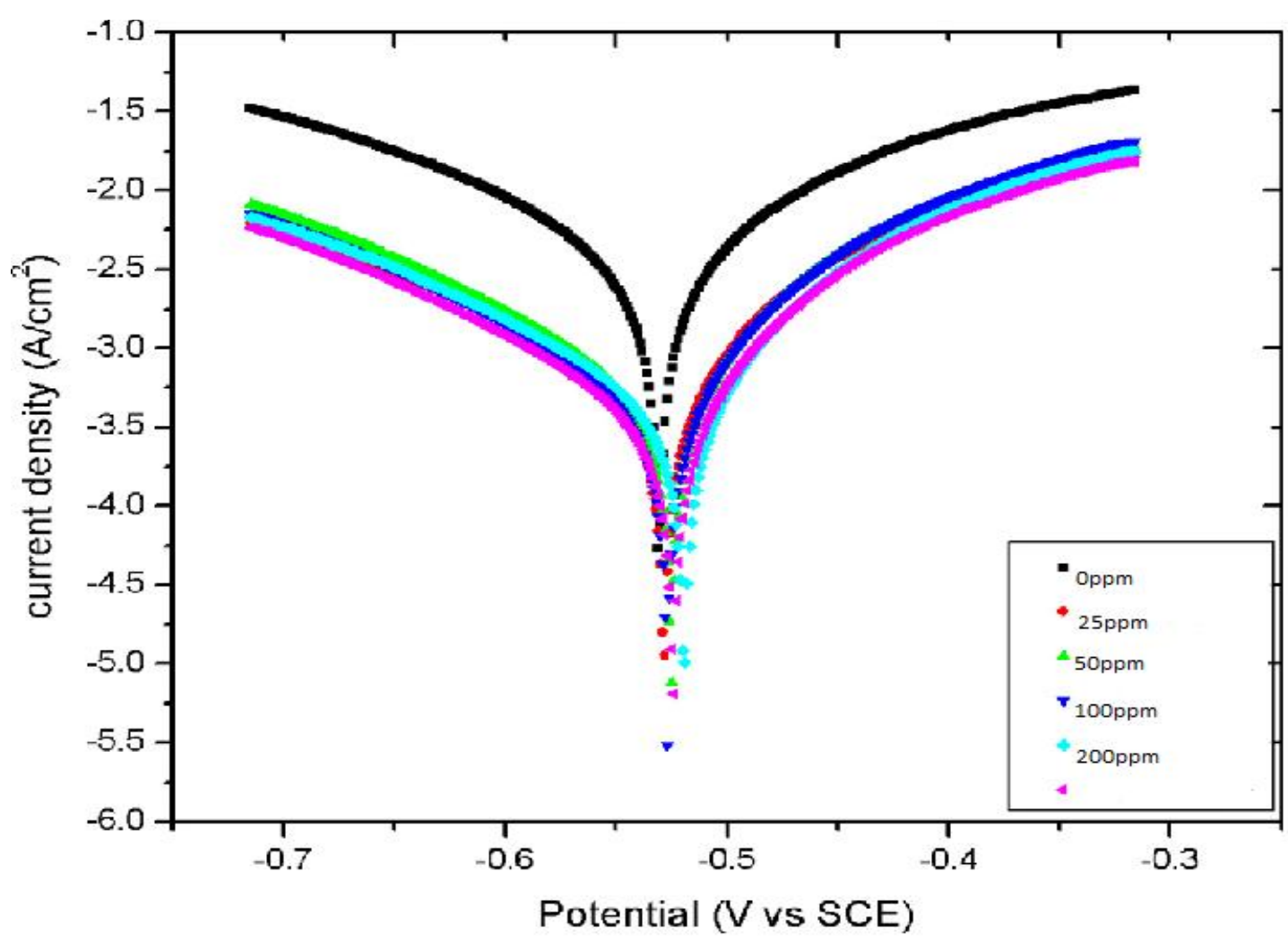

Fig. 12:- Tafel plots for mild steel corrosion in $2 \mathrm{M}$ hydrochloric acid in the absence and the presence of various concentration of $\mathrm{BPH}$ inhibitor

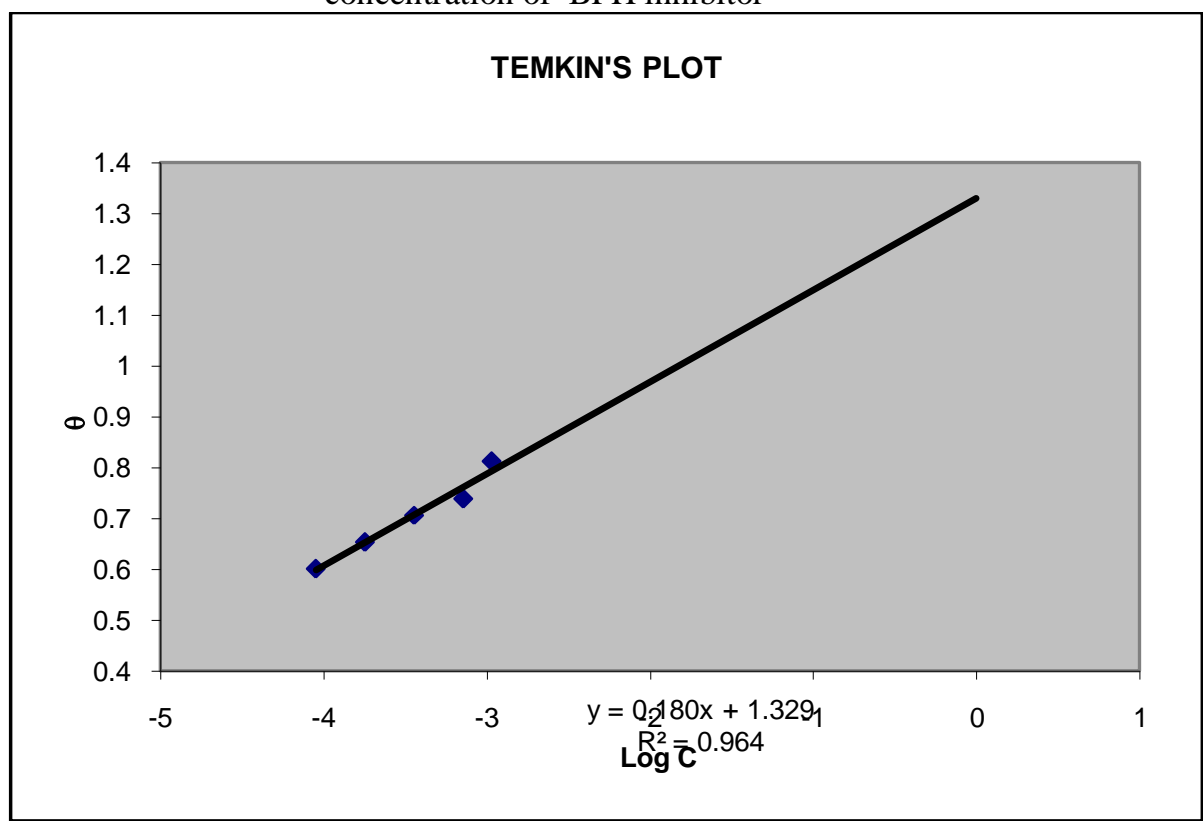

Fig:13:- Temkin's plot for mild steel specimen exposed in 2M HCl medium in presence of BPPH at 303K 


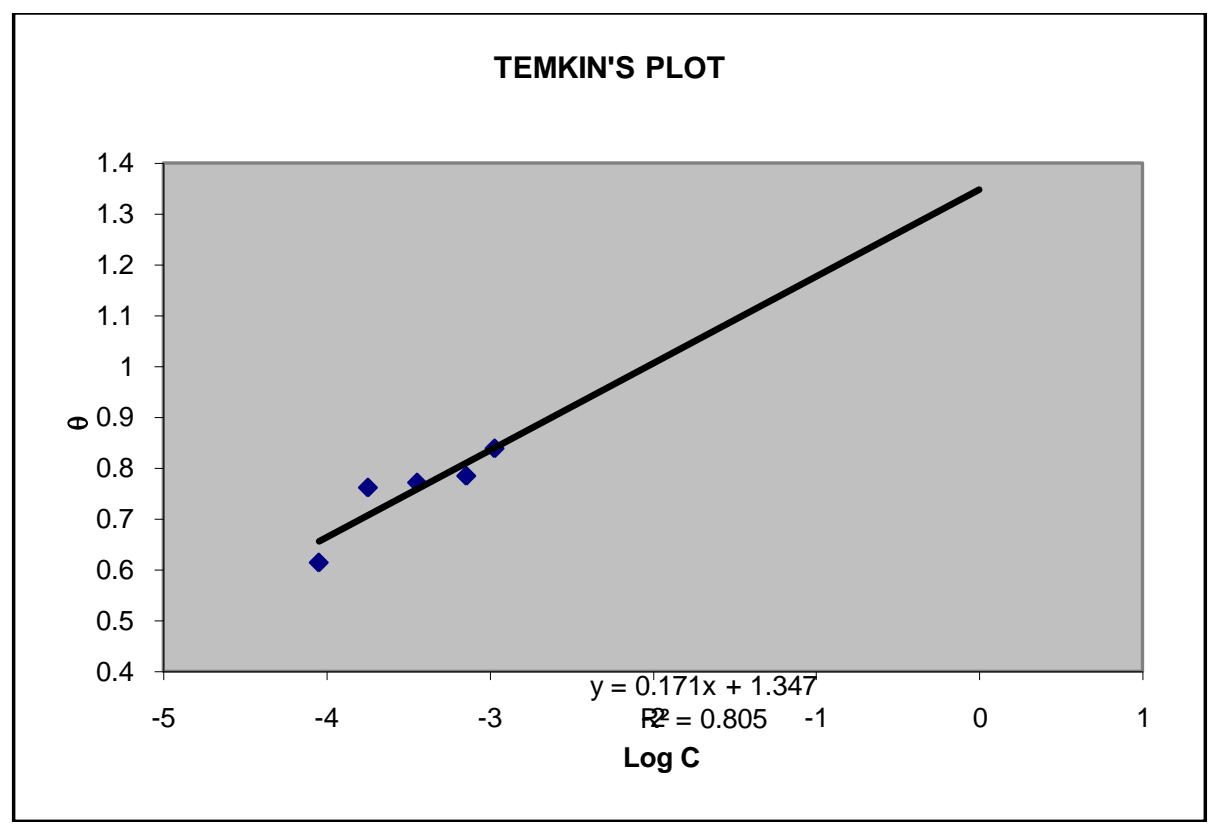

Fig:14:- Temkin's plot for mild steel specimen exposed to $2 \mathrm{M} \mathrm{HCl}$ medium in presence of BPPH at $303 \mathrm{~K}$

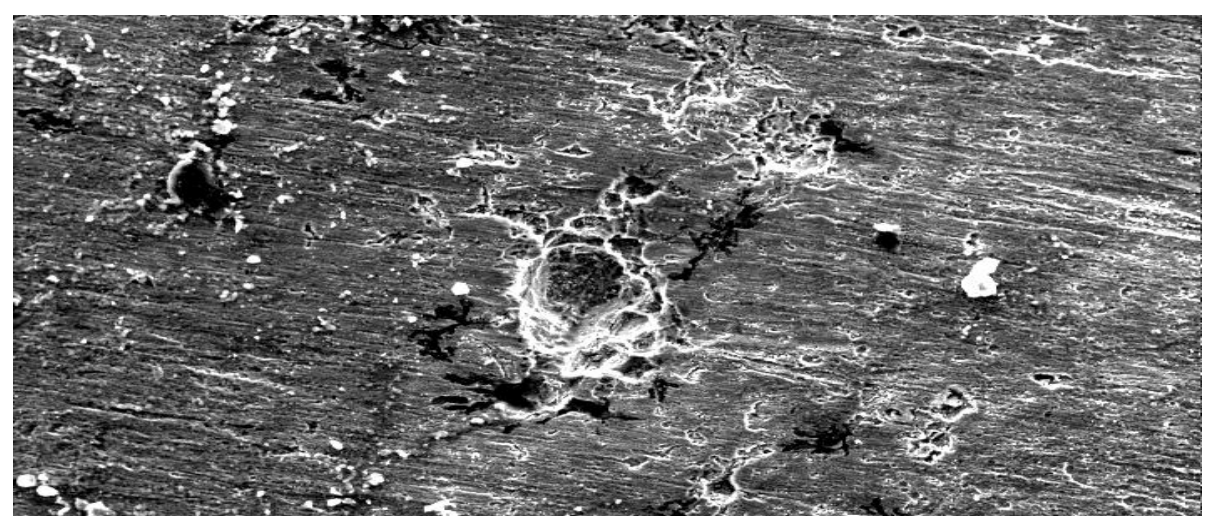

Figure 15:- Micrograph of brightly polished surface exposed to $2 \mathrm{M} \mathrm{HCl}$

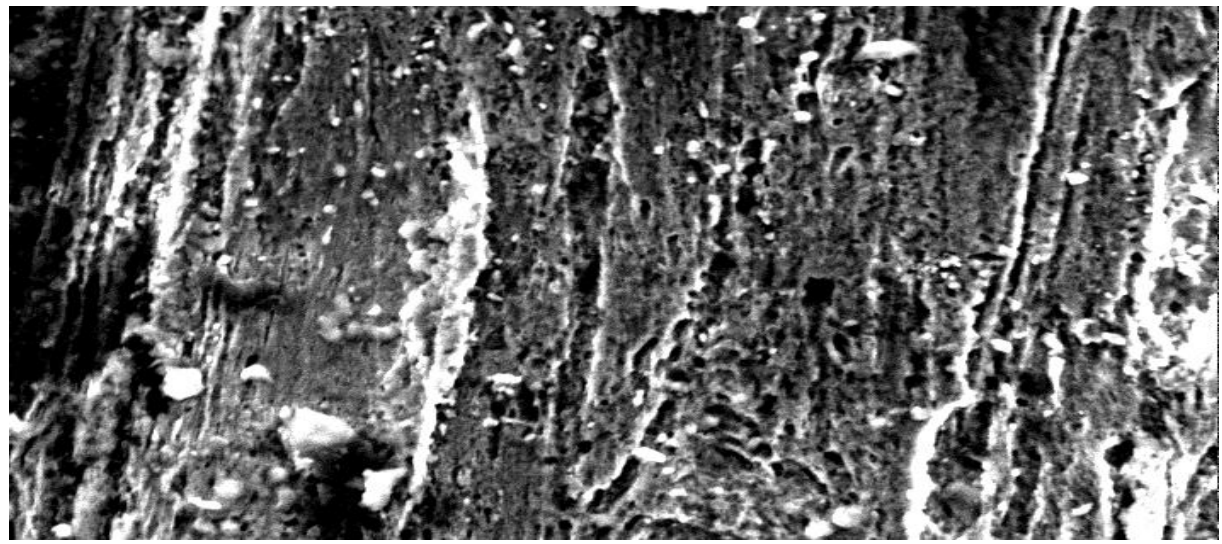

Figure. 16:- SEM analysis of MS surface exposed to $2 \mathrm{M} \mathrm{HCl} \mathrm{(BPPH)}$ 


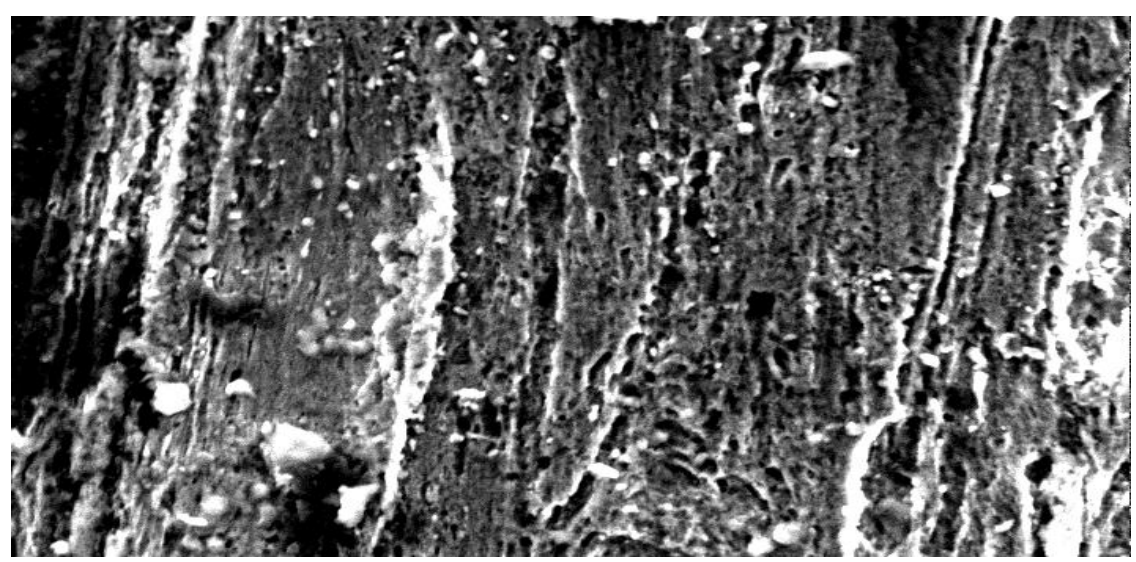

Figure 17:- SEM analysis of MS surface exposed to $2 \mathrm{M} \mathrm{HCl}(\mathrm{BPH})$

Table 4:- Calculated quantum chemical parameters of the studied inhibitors.

\begin{tabular}{|c|c|c|}
\hline Quantum parameters & BPH & BPPH \\
\hline $\mathrm{E}_{\text {номо }}(\mathrm{eV})$ & -5.7563 & -5.0425 \\
\hline $\mathrm{E}_{\text {LUMO }}(\mathrm{eV})$ & 0.0133 & 0.1080 \\
\hline$\Delta E$ gap $(\mathrm{eV})$ & 5.77 & 4.93 \\
\hline$\mu$ (debye) & 1.64 & 2.57 \\
\hline $\mathrm{I}=-\mathrm{E}_{\text {номо }}(\mathrm{eV})$ & 5.7563 & 5.0425 \\
\hline $\mathrm{A}=-\mathrm{E}_{\text {LUMO }}(\mathrm{eV})$ & -0.0133 & 0.1080 \\
\hline$\chi=\frac{I+A}{2}$ & 2.8715 & 2.5752 \\
\hline$\eta=\frac{I-A}{2}$ & 2.8848 & 2.4672 \\
\hline$\sigma=\frac{1}{\eta}$ & 0.3466 & 0.4053 \\
\hline$\omega=\mu^{2} / 2 \eta$ & 0.4661 & 1.3385 \\
\hline$\Delta N=\frac{\chi_{\mathrm{Fe}}-\chi_{\mathrm{inh}}}{2\left(\eta_{\mathrm{Fe}}+\eta_{\mathrm{inh})}\right.}$ & 0.7155 & 0.8967 \\
\hline $\mathrm{TE}(\mathrm{eV})$ & $\begin{array}{l}-17190.64 \\
\end{array}$ & -23477.42 \\
\hline
\end{tabular}<smiles>NN=C1CCN(Cc2ccccc2)CC1</smiles>

N-benzyl piperidine -4-one hydrazone(BPH)

Figure:18a

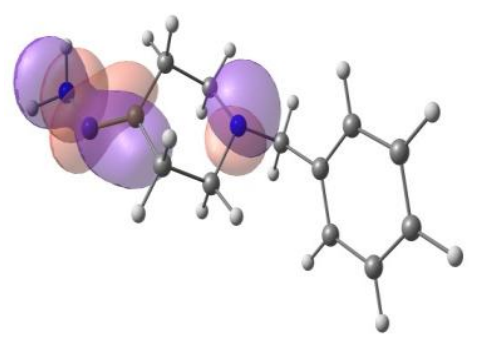

HOMO

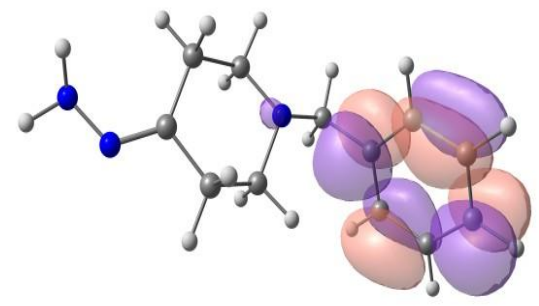

LUMO 


\section{Figure:18b}

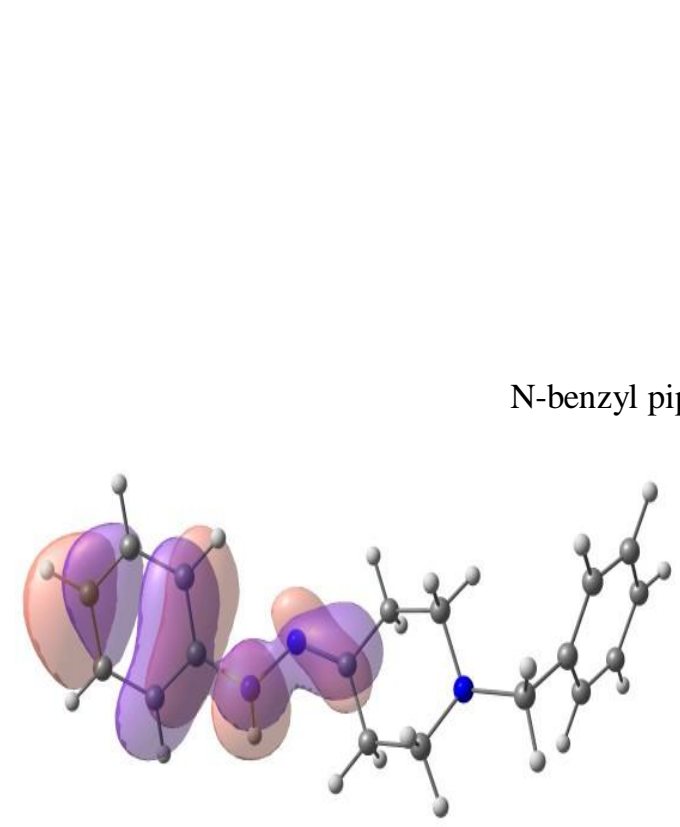

HOMO

Figure:19b
Figure:18c<smiles>c1ccc(CN2CCC(=NNc3ccccc3)CC2)cc1</smiles>

\section{Figure:19a}

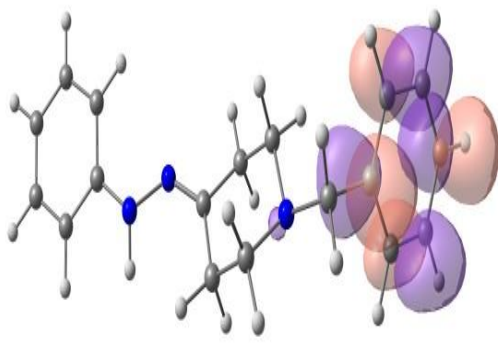

LUMO

\section{Figure:19c}

Quantum studies done for BPPH and BPH with its $\mathrm{E}_{\mathrm{HOMO}} \& \mathrm{E}_{\mathrm{LUMO}}$ is shown in Figure 18 and 19. $\mathrm{E}_{\mathrm{HOMO}}$ of BPPH and $\mathrm{BPH}$ is $-5.0425 \mathrm{eV}$ and $-5.7563 \mathrm{eV}$ that of its $\mathrm{E}_{\mathrm{LUmO}}$ is $0.1080 \mathrm{eV}$ and that of its $\mathrm{E}_{\mathrm{Lumo}}$ is $-0.0133 \mathrm{eV}$ The high $\mathrm{E}_{\mathrm{HO} о}$ value of $\mathrm{BPPH}$ and $\mathrm{BPH}$ indicates the good inhibiting nature of $\mathrm{BPPH}$ and $\mathrm{BPH}$. Moreover energy diagram of HOMO revealed that the protection of BPPH and BPH is due to lone pair of electrons in two nitrogen atoms of hydrazone moiety, ring nitrogen and $\pi$ electrons present in the benzene ring of the molecule. . Compounds I (BPPH) has more inhibitory effect compare to compound II (BPH) due to two nitrogen atoms, ring nitrogen and two phenyl rings where as compound (II) has two $\mathrm{N}$ atom, ring nitrogen and only one phenyl ring. The smaller the $\Delta \mathrm{E}$ value is, the greater is the reactivity of a molecule. ${ }^{16}$ The trends in the $\Delta \mathrm{E}$ values for the studied compounds show that BPPH is the most reactive compound while BPH is the least reactive compound. Values of $\Delta \mathrm{N}$ can be used to show that inhibition effect resulted from electron donation. As posited by Lukovits, if $\Delta \mathrm{N}<3.6$, then inhibition efficiency most likely increased with increasing electron donating ability at the metal surface. ${ }^{[17]}$

\section{Conclusion:-}

The following results can be inferred from the present investigation. The experimental data shows that BPPH and $\mathrm{BPH}$ are effective inhibitors for the mild steel corrosion in the investigated temperature rang and its inhibition efficiency increases with the increases in its concentration and decreases with in increases in temperature. The inhibitors act as a mixed inhibitors. The adsorption of investigated compounds on to the mild steel obeyed Temkins adsorption isotherm. The results obtained from weight loss measurements, Tafel polarization curves and EIS are in reasonable agreement. Compound $\mathrm{I}(\mathrm{BPPH})$ exhibits exellent inhibition power due to two phenyl rings, two nitrogen and ring nitrogen in it wheres BPH has only one phenyl ring in N-benzyl moiety of the molecule .Quantum chemical studies indicate that the two nitrogen atoms, phenyl ring and ring nitrogen were the main adsorption centers for the corrosion inhibiton action. The agreement with the experimental data was also found to be satisfactory. 


\section{References:-}

1. S.A. Umoren, I.B. Obot, E.E. Ebenso, P.C. Okafor: Portugaliae Electrochim.Acta., 26 (2008) 26, 267-282.

2. E.E. Ebenso: Bull. Of Electrochem.,19 (5), (2003) 209-216.

3. N.O. Eddy and E.E. Ebenso: African J. Pure Appl. Chem., 2 (6), (2008) 046-054.

4. H.E. El Ashry, A. El Nemr, S.A Esawy, S. Ragab: Electrochem. Acta., 51 (2006) 3957- 3968.

5. H.Wang, X. Wang, L. Wang, A. Liu: J.Mol.Model., 13 ( 2007) 147-153

6. Umoren S.A., Obot I.B., Ebenso E.E., Corrosion inhibition of aluminium using exudate gum from Pachylobus edulis in the presence of halide ions in HCl, E-Journal of Chemistry, 5(2), 355 (2008)

7. K.R. Trethewey, J. Chamberlain, Corrosion for Science and Engineering, second ed., Longman, London, 1995.

8. S.R. De Sanchez, D.J. Schiffrin, Flow corrosion mechanism of copper base alloys in seawater in the presence of sulphide contamination, Corros. Sci. 22 (1982) 585-607.

9. A. Neville, C. Wang, Erosion-corrosion mitigation by corrosion inhibitors-an assessment of mechanisms, Wear 267 (2009) 195-203.

10. Senthilkumar A N, Tharini K, Sethuraman M G Surf Rev Lett,2009, 16,1, 141.

11. Senthilkumar A N, Tharini K, Sethuraman, M G J.Mater.Engg \& Perform. 2011, 26, $\quad 2,969$.

12. Cheng, X.L., Ma, H. Y., Chen, S .H., Yu, R., Chen, X., Yao, Z. M.: Corrosion of stainless steels in acid solutions with organic sulfur-containing compounds. Corrosion Science 41(2), 321-323 (1999).

13. Elmorsi, M A.: Using acrylamide and oligo (oxyethylene) methacrylate in corrosion protection of steel. Corrosion Science 41(2), 305-320 (1998) .

14. Baliah, V., Noller, C.R.: The Preparation of Some Piperidine Derivatives by the Mannich Reaction. Journal of American Chemical Society 70(11), 3853-3855 (1948)

15. Ebenso, E.E., Okafor, P.C., Ekpe, U.F.: Studies on the Inhibition of Aluminium Corrosion by 2-Acetylpheno Thiazine in Chloro Acetic Acid. Anti Corrosion Methods and Materials 50(6), 414- 421 (2003).

16. N.O.Eddy,Mol.Simul.35(5) (2010) 354.

17. I.Lukovits,A.Shaban,E.Kalman,Russian J.Elctrochem. 39(2003) 177. 